\title{
Constructive interpersonal leadership relations in knowledge-based organisations: A theoretical framework
}

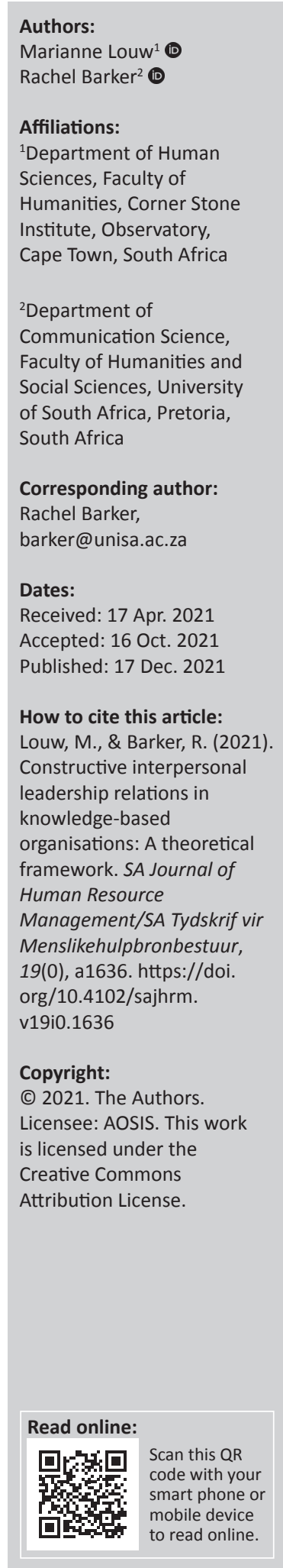

Orientation: Acknowledging the need for a deeper understanding of interpersonal communication as part of interpersonal leadership in knowledge-based organisational contexts.

Research purpose: This study aimed to propose a theoretically based definition of constructive interpersonal leadership relations (ILRs) and a generic model of ILR with guidelines for fostering constructive ILR in knowledge-based contexts.

Motivation for the study: Emerging trends showed knowledge-based organisations presented unique sets of challenges for constructive ILR in South Africa.

Research approach/design and method: We conducted a qualitative study using the interpretivist research paradigm. Two convenience samples were used for the data collection: semi-structured in-depth interviews with eight experts in the field, and 31 questionnaires were sent to leaders or followers that examined the micro-perspective in knowledge-based organisations in South Africa. The data analysis and interpretation were performed by thematic analysis.

Main findings: We established that the leader-follower dyad is the locus of interpersonal leadership, and that in constructive ILR, leaders or followers actively and mutually nurture the leader-follower dyad, that leaders oversee these relationships without using a formal hierarchy and that the leader-follower interaction has meaning on informational and relational levels.

Practical/managerial implications: The findings can be used by leaders in knowledge-based organisations as useful guidelines to create and maintain an organisational environment that is supportive of constructive ILR.

Contribution/value-add: This study provides insight into personal attributes relevant for ILR in knowledge-based organisational contexts.

Keywords: interpersonal leadership relations; interpersonal leadership communication; knowledge-based organisations; leader-follower dyad; symbolic interaction.

\section{Introduction}

'[My leader $]$ is a person of very few words, but there is a good understanding between us ... We don't have to continually reassure one another of the authenticity of the relationship ... It's based on mutual respect ... In any organisation, the leader-follower relationship that undergirds that communication is of pivotal importance. I interact with other leaders who have a lot more of a buzz in their communication, yet the level of the interpersonal relationship is not as clear, and neither is the communication.' (Kate, 20 years of knowledge work, Interview 8)

\section{Orientation}

Extensive research studies have been conducted on leadership and communication in organisations. A research study conducted by Blake, Leach, Robbins, Pike and Needleman (2013) showed a significant relationship between leadership and employees' intention to leave the organisation. Several authors emphasised the importance of ethical leadership and the role of leaders' behaviours in enhancing subordinates' perceptions of task significance, motivation, job satisfaction, employee attitudes, emotional and interpersonal competencies, and change management (Alban-Metcalfe \& Alimo-Metcalfe, 2013; Gentry \& Sparks, 2012; Hackman \& 
Johnson, 2013; Piccolo, Greenbaum, Den Hartog, \& Folger, 2010; Riggio \& Lee, 2007). Testa and Sipe (2012) identified 20 important competency categories, which they labelled under 'business savvy', 'people savvy' and 'self-savvy.' In their resultant model, interpersonal communication is included under 'people savvy.' Although this suggests a relationship between leadership and communication, this relationship has not been formalised at an interpersonal level.

\section{Research purpose and objectives}

The purpose of this study was therefore to address this gap and obtain deeper insights and knowledge on the concept henceforth termed as interpersonal leadership relations (ILR), with specific reference to knowledge-based organisational contexts. The three main objectives were to propose the following: a theoretically based definition of constructive ILR, a generic model of ILR and guidelines for encouraging constructive ILR in knowledge-based contexts.

\section{Literature review}

Knowledge workers are appointed based on the knowledge of a specific subject matter, not their ability to perform manual labour (Serrat, 2017). Their work outputs are usually intangible, analytical, creative and often digital (Jarrahi \& Thomson, 2017, p. 1073). In this study, the term 'knowledge workers' was defined as professional experts who produce, integrate and share specialist knowledge and ideas as their primary contribution to the organisation. Indriati, Tjakraatmadja, Rudito and Thoha (2016, p. 25) argued that knowledge-based organisations are critical for the capacity and future sustainability of many organisations by dispersing new knowledge and connecting ideas (Goffee \& Jones, 2013). This emphasises the important role of leadership that Tannenbaum et al. (2013, p. 24) defines as 'interpersonal influence, exercised in situation and directed, through the communication process, toward the attainment of specified goals.' Hence, leadership is defined as interpersonal influence through (symbolic) communication towards a relational or functional goal.

Tannenbaum et al. (2013) further stated that leadership involves attempts by a leader (influencer) to affect (influence) the behaviour of a follower (influencee) or followers in a situation, where a follower is seen as the influencee whose behaviour is influenced through communication towards a relational or functional goal. In this research article, the concept of leader/followers is introduced because of the growing interest in active followership (Hoption, 2014); the argument by Howell and Shamir (2005, p. 97) that followers play an 'active role in constructing the leadership relationship, empowering the leader and influencing his or her behaviour, and ultimately determining the consequences of the leadership relationship,' and that the focus is interpersonal. Therefore, the concept 'leader/follower' denotes situations where interpersonal communication is taking place between an individual with the person directly above or below him or her in the organisational hierarchy. A leader/follower is considered as an individual who, as the situation requires, may alternatively lead or follow another individual in an interpersonal process of mutual influence towards a relational of functional goal.

McDermott (2009) identified the specific criteria for the degree to which an interaction is seen as interpersonal, of which the following are relevant to this context: a small number of communication participants, a face-to-face or otherwise immediate medium, feedback (which coincides with contemporary leadership approaches) and mutual influence (which is also in line with the latest leadership models). Interpersonal leadership communication (ILC) is, therefore, defined as a symbolic interaction between two to five leaders and followers to share meaning and mutually influence each other at a relational and a functional level.

Watzlawick, Beavin Bavelas and Jackson (2011) described the ongoing dyadic relationships (long-lasting relationships that are important to both partners, including some professional relationships) as open systems, and therefore, the leader-follower dyad (LFD) is considered as an open system. This study centres on the LFD between two employees who are directly and vertically linked in the organisational hierarchy.

As the terms 'leader-follower dyad (LFD)' and 'interpersonal leadership communication (ILC)' are very strongly interrelated, the term ILR was adopted in this study to denote that relationship (not the leader or follower) as the locus of leadership in order to portray leadership communication between leader/followers as a process (as opposed to an event), and to indicate that ILC is explored within enduring dyads, rather than fleeting interactions. Based on this discussion, the following definition was developed:

Constructive interpersonal leadership relations (ILR) in a knowledge-based organisational context is a dyadic process of symbolic communication between two expert leader/followers who mutually influence each other and share meaning to strengthen their relationship and to collaboratively transfer and apply knowledge to achieve organisational goals.

The systems theory was used as the first metatheory of the study (Littlejohn \& Foss, 2008) because of its emphasis on interdependence between leader/followers, rather than on individuals. It emphasises the importance of environmental influences on ILR, but at the same time allows for exploration of element attributes (individual leader/ follower traits).

The symbolic interactionism (SI) theory was the second metatheory of the study (Burns \& DeVillé, 2017; Tannenbaum et al., 2013) because from this perspective, meanings are social products of interaction. Thus, the meaning of a word is not the object to which it refers but the response it evokes in the context. Symbolic interactionists do not view 'mind' as 
primarily psychological but rather as social. They prefer to refer to 'minding' (a verb), which occurs when a leader/ follower pauses to interpret a situation from the collective meanings that she or he has learned through social interaction. Symbolic interactionists view people as social beings whose individual identities are emerging social products. This includes two aspects of the self: the self-as-process (the $I$ ) and the self-as-object (the me). A person is born with an $I$, his or her spontaneous response to social situations. The self-asobject develops through social interaction and directs the I. People constantly reflect on themselves and their relationships, engaging in mindful, symbolic action and negotiating meanings.

The implications of SI in this study are as follows: ILR is symbolic interaction, where meaning depends on mutual interpretation; meaning is co-created by leader/followers, is influenced by the context of the particular LFD, and is dynamic; ILR contributes to creating and modifying the organisation as a social institution; the identities of the leader/followers are social products that are influenced by ILR. Therefore, an examination of ILR cannot focus on the leader to the exclusion of the follower and the context but must focus on the symbolic interaction.

Various theories of leadership are prevalent in a meta-analysis of empirical leadership studies published in prominent organisational behaviour journals (Gill, 2011; Glynn \& DeJordy, 2010; Miller, 2002; Winkler, 2010). The relative relevance of each perspective to this study is summarised, as shown in Table 1. In the header row of the table, the metatheories are summarised, and in each column, the leadership perspectives are summarised in order of relevance to the metatheory.

Table 2 summarises the theoretical models of leadership communication that relates most to ILR in terms of the two metatheories (Barrett, 2006; Johansson, Miller, \& Hamrin, 2014; Mitchell, 2014; Rokeach, 1973).

As shown in Table 2, it is postulated that the perspectives most pertinent to this study are social constructionism, the basic axioms of relational communication, Rokeach's comprehensive theory of change, the five axioms of relational communication and attribution theory.

TABLE 1: Leadership perspectives relevant to this study.

\section{The systems theory}

The LFD is a system consisting of interdependent parts (leader or followers) whose

interaction creates a unique whole that comprises more than the two individuals. The

LFD exists within suprasystems and an environment that influences and are influenced

by the interaction.

Constructionist relational leadership

- Leader/followers are interdependent

- The role of the context is emphasised

- Interpersonal leadership is a system with leadership, organisational and environmental

aspects

- There are interdependent connections between the organisation and leader/follower

members

- Leaders should balance authenticity and adaptation in the context

Organic leadership

- Leader/followers are interdependent, sharing accountability

- Control is exercised through group dynamics (not formal structures)

- Because of the dynamic environment, interpersonal leadership requires adaptation

Shared leadership

- Leader/followers are interdependent

- Leader-follower relations shift in a dynamic network

Spiritual leadership

- Meaningful purposes and shared values forge connections between leader/followers

Symbolic interactionism

The members of the dyad communicate symbolically, sharing meaning about their

tasks and their relationship. Although this process is affected by pre-existing societal, organisational and relational norms, it also creates the dyad and its surrounding social structures.

\section{Constructionist relational leadership}

- Leader/followers create shared meaning-making patterns with multiple emerging meanings

- Leader-follower relationships (not leaders) are the locus of meaning and leadership

- Leadership is a social construct created through ILR

- No clear distinction between a leader and follower; both consciously and mutually influence each other

\section{Organic leadership}

- Reciprocal actions between leader/followers are emphasised

- Leader/followers interact as sense-making partners

- Interaction is a form of leadership

Shared leadership

- The roles of the leader and follower are interchangeable

- Collaborative interpersonal relationships are fundamental

Spiritual leadership

- Leader/followers redefine meaningful purposes and shared values through interaction

LFD, leader-follower dyad; ILR, interpersonal leadership relations.

Based on the summary in Table 1, it is argued that constructionist relational leadership is the most relevant leadership perspective that pertains to this study from both metatheories

TABLE 2: Interpersonal communication theories relevant to this study.

\section{The systems theory}

The LFD is a system consisting of interdependent parts (leader/followers) whose interaction creates a unique whole that comprises more than the two individuals. Th

LFD exists within suprasystems and an environment that influence and are influenced by the interaction.

\section{Social constructionism}

- ILR creates unique social meanings; thus, the LFD becomes more than the sum of its

parts

- The social meanings in the LFD influence and are influenced by larger suprasystems (e.g. the organisation)

\section{Rokeach's comprehensive theory of change}

- Interaction between leader/followers with unique attributes creates holism in the LFD, where the dyad is more than the sum of its parts

\section{The basic axioms of relational communication}

- The informational and especially the unique relational meanings create holism in the LFD (Axiom 2)

- Leader/followers organise their interactions into meaningful patterns to retain and restore balance in the LFD (Axiom 3 )

Attribution theory

- How the leader/followers attribute causes to each other's behaviour affects ILR

LFD, leader-follower dyad; ILR, interpersonal leadership relations.
Symbolic interactionism

The members of the dyad communicate symbolically, sharing meaning about their tasks and their relationship. Although this process is affected by pre-existing societal,

organisational and relational norms, it also creates the dyad and its surrounding social structures.

Social constructionism

ILR determines the construction of reality and the experience of reality influences ILR

The basic axioms of relational communication

- Every leader-follower interaction contributes informationally and relationally to the definition to the relationship (Axiom 2)

Leader/followers punctuate their interactions into meaningful patterns to make sense of ILR (Axiom 3)

Rokeach's comprehensive theory of change

- Leaders/followers' values, beliefs and attitudes influence how they make sense of ILR

Attribution theory

- Leader/followers attribute causes to each other's behaviour to define the LFD 


\section{Research design Research approach}

A qualitative research approach was followed because it facilitates an in-depth investigation of complex data (Ary, Jacobs, Irvine, \& Walker, 2018, p. 379; Saldaña, 2016). Qualitative research is more pragmatic than quantitative designs, and allows the exploration of unexpected data and rich data (Locke, Silverman, \& Spirduso, 2010). Because ILC is a largely unexplored topic in communication research, a qualitative approach was deemed to be suitable for this study.

\section{Research strategy and method}

Sample 1 (ILR experts) consisted of eight semi-structured, in-depth interviews, whilst Sample 2 (leader/followers working in knowledge-based contexts) consisted of a total 55 with a realised sample of 31 completed questionnaires. A phenomenological approach was used in the interviews (mostly through open-ended questions) to explore participants' experiences and the meaning they make of those experiences. Meaningfulness does not reside in the lived experience itself but is opened through intentional attention. As they reconstruct and reflect on their experience, participants engaged therein (Schutz, 1967; Seidman, 2013).

\section{Research setting}

The unit of analysis is the phenomenon that is being studied and was identified as an individual, particularly, the individuals who expressed views on ILR and related phenomena relevant to this study (Collis \& Hussey, 2017, p. 101). Two populations were identified: Population 1 included all individuals who are experts at ILR (e.g. authors, lecturers, training facilitators, business coaches and consultants in relevant fields), and Population 2 comprised leader/ followers practising ILR in knowledge-based organisations. Sample 1 (interview participants) was drawn from Population 1, whilst Sample 2 (questionnaire participants) was selected from Population 2.

Non-probability sampling (Bryman \& Bell, 2015) was used, which is considered highly suitable for qualitative research and requires neither statistical representation nor scale. Qualitative samples are often limited to a small number of locations or interests, so that the context of the study is known (Ritchie et al., 2014). The following types of non-probability sampling were used: purposive sampling, where units are selected based on specific criteria, and convenience sampling, where units are recruited because they are easily accessible. Through these sampling methods, two samples were recruited: Sample 1 consisted of eight individuals who are experts in ILR and related fields. Sample 2 consisted of 31 people who are known to the researchers and are interpersonal leader and followers in knowledge-based organisational contexts.

\section{Data collection methods}

The following data collection methods were used: semistructured in-depth interviews for Sample 1 (experts) and questionnaires for Sample 2 (leader/followers). Semistructured interviews are flexible and very suitable for qualitative studies. In this study, the interviews yielded rich data for describing ILR, and data saturation was reached after eight interviews. The questionnaires examined the micro-perspective and contained mostly open-ended questions and yielded interesting data, although not as rich as those from the interviews. The questions were distributed as follows: four questions were used for introductory and demographic information; one explored Theme 1 (the organisational environment), seven focused on the participants' ILR (Theme 2); two questions examined individual leader/follower attributes (Theme 3) within that relationship; and the concluding question allowed for any information that the participant wished to add. The response rate to the questionnaires, although adequate, was disappointing. In addition, two questionnaires had to be discarded, because participants had ostensibly misinterpreted the general aim of the questions.

In order to ensure reliability and replicability of the findings, the 12 recommended transparency criteria proposed by Anguinis and Solariono (2019, p. 1292) were used to ensure translucence and replicability, and according to them, from an 'ontological perspective is dominant in strategy in that a key goal is to produce replicable and cumulative knowledge.' The following criteria were applied to the interviews to access the degree of transparency: the kind of qualitative method (interviews), insider-outsider continuum (relationship with participants or organisations), sampling procedures (nonprobability sampling, specifically purposive and convenience sampling), relative importance of participants or cases (experts at ILR and leader/followers practising ILR in knowledge-based organisations), documenting interactions (transcriptions), saturation point (no new insights or themes), unexpected opportunities and challenges (changes in access to data), management of power imbalance (no influencing during the research process), data coding (descriptive coding), data analysis (implicit and explicit dimensions and structures during coding), and data disclosure (raw material, transcripts and recordings).

Trustworthiness was measured by four criteria: credibility ('internal validity' in positivistic research), transferability ('external validity' or 'generalisability' in positivistic research), dependability ('reliability' in positivistic research) and confirmability ('objectivity' in positivistic research) (Maree, 2012; Shenton, 2004). In order to ensure credibility, there was enough interaction between the researchers and the participants during the interviews, allowing for verbal and non-verbal communication cues, and clarification of questions and terms. The research findings were presented to the participants, and based on their responses, the study was found to be highly credible. In terms of transferability, the research methodology and conceptual framework are sufficiently detailed to enable other researchers to repeat the study, more than one data collection method was used, and interviews were transcribed. Whilst findings will not be 
identical, other studies employing the same conceptual framework should produce comparable findings. In order to ensure dependability, the methodology and conceptual framework were described in ample detail to allow other researchers to repeat the study. A lay review was carried out, in that questionnaire participants were invited to judge the confirmability of the study and found it acceptable. No external party had a vested interest in a specific outcome.

In terms of ethical considerations, ethical clearance was obtained from the University of South Africa to continue with the study. Informed consent was provided by all participants, and the confidentiality of their responses was ensured. No harm to participants was foreseen or noted. Plagiarism was avoided through meticulous referencing to original authors, and by submitting the thesis to Turnitin, a website employing software that checks for plagiarism.

\section{Data analysis and reporting}

Thematic analysis was used for the data analysis and interpretation method as a form of qualitative content analysis. According to Cassell (2015), thematic analysis comprises the thematic grouping of textual data according to a template of codes, some of which are predefined and some of which emerge from the process of analysis and is therefore a flexible technique for semi-structured interviews. Ryan and Bernard (2003, p. 87) defined themes as 'abstract (and often fuzzy) constructs that link... expressions found in text.'

This study was executed from a phenomenological stance, which, according to Bazeley (2013), uses thematic statements to identify the elements of a phenomenon. Hence, a primarily deductive approach to analysis was taken, where the texts were analysed for codes relating to themes already identified in the conceptual framework. Four coding cycles were applied: pre-coded categories were used to develop questions for the interviews and questionnaires; codes were used to describe the themes and subthemes; coding was used to detect patterns between themes and subthemes; and then a theoretical framework for ILR was developed. Whilst timeconsuming, the thematic analysis yielded rich descriptions of ILR and made meaningful contributions towards establishing a theoretical framework.

\section{Findings}

The findings are discussed in terms of the three research objectives of the study.

\section{Objective 1: Propose a definition of constructive interpersonal leadership relations}

Based on the findings, constructive ILR in a knowledgebased organisational context is defined as follows:

A dyadic process of symbolic interaction between two expert leader/followers who mutually influence each other and share meaning to strengthen their relationship and to collaboratively transfer and apply knowledge to achieve organisational goals.
Several significant concepts emerge from this definition. Firstly, whilst a small group of communication participants could still engage in ILC, the focus of this study was on dyadic communication between two participants. It is posited that many of the tenets of dyadic ILC could also apply to small groups; however, it must also be assumed that group dynamics (absent in dyadic communication) would affect these or add others. Furthermore, the adjective 'expert' denotes that these individuals possess knowledge and skills valuable to the organisation, and that they, therefore, constitute intellectual capital in the organisation. Secondly, the term 'leader/followers' is used to denote a relationship, in which the leader and follower roles are not static but may be exchanged between the two communicators, based on superior knowledge in the particular context. This notion is emphasised by the reference to mutual influence, which is a systems principle and contradicts traditional views of the leader unilaterally influencing a passive follower.

Thirdly, the aim of ILR is to 'share meaning', a principle of SI. Therefore, in this context, shared meaning refers to both relational and informational meaning in accordance with the theory of relational communication. This shared meaning performs two purposes: the strengthening of the leaderfollower relationship (the highest priority of the two), and the collaborative transference and application of knowledge (which often flows naturally from achieving the relational purpose) in service of organisational goals (the functional objective of knowledge workers as intellectual capital). Fourthly, the term 'constructive' is used to denote ILR that enhances rather than detracts from relationship building and knowledge sharing.

\section{Objective 2: Develop a generic model of interpersonal leadership relations}

Based on the findings of this study, Figure 1 represents a generic model of ILR, containing the elements that are common to all instances of ILR in knowledge-based contexts.

As indicated in Figure 1, the context is knowledge-based, and the focus is on any LFD (system) within that environment, consisting of two experts (knowledge workers) who constitute intellectual capital for the organisation. These experts are termed leader/followers because their leadership roles may shift according to the knowledge demands of the situation. Both leader/followers engage in mutual symbolic interaction, sharing meaning at a relational level (to reinforce their relationship) and at an informational level (to transfer, develop and retain knowledge). In doing so, their communication is influenced by their values and competencies related to ILR. Because of the symbolic interaction in the LFD (system), the dyad develops emergent properties that are unique to that relationship. The LFD may also contribute outputs to its organisational environment.

According to the systems theory, any open system is influenced by its dynamic environment, and therefore, the constructs may vary in relevance as the time passes and 


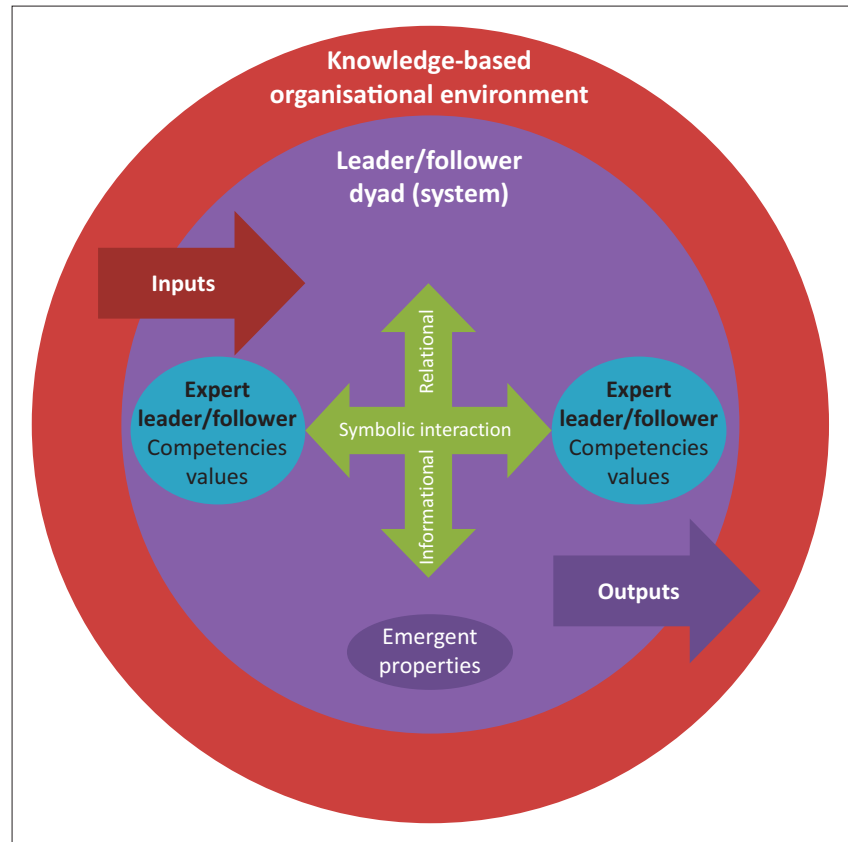

FIGURE 1: General model of interpersonal leadership relations.

economic, political and organisational environments change in unanticipated ways.

\section{Objective 3: Propose guidelines for an organisational environment that supports constructive interpersonal leadership relations}

Table 3 summarises the findings on the key constructs of an organisational environment that supports constructive ILR.

It was found that the LFD (not the leader) is the locus of interpersonal leadership. This means that both leader/ followers mutually nurture the LFD, and that leaders manage these relationships without using the formal hierarchy. The nature of the LFD is determined by verbal and non-verbal ILC. Every leader-follower interaction has meaning on both an informational (content) level and a relational level (the implications of the communication for the LFD).

Two secondary research objectives were also addressed. The first was to describe interpersonal leader/followers' experiences of ILR in knowledge-based contexts, with a view to understand what leader/followers consider constructive ILR. The relevant key constructs that emerged are summarised in Table 4.

The behaviours listed in Table 4 are thus the those that interpersonal leaders could consider practising to strengthen their LFDs and efficiently share and apply knowledge. In some cases, they also stand in direct contrast with specific destructive ILC behaviours that should be avoided in ILR.

The second secondary research objective was to identify individual leader/follower attributes that enhance ILRs, as summarised in Table 5.
TABLE 3: An organisational climate that supports constructive interpersonal leadership relations.

\begin{tabular}{|c|c|}
\hline Aspect & Contributing practices \\
\hline \multicolumn{2}{|c|}{ Collaborative leadership concept } \\
\hline Transparency & $\begin{array}{l}\text { - Encourage followers to present new ideas and listen to them } \\
\text { - Show flexibility to adopt new ideas from followers } \\
\text { - Encourage free expression of diverse opinions } \\
\text { - Euide expert followers to make their own decisions } \\
\text { - Ensuin strategic decisions to followers } \\
\text { and uncertainty }\end{array}$ \\
\hline Empowerment & $\begin{array}{l}\text { - Allow followers to provide a valuable intellectual capital } \\
\text { instead of merely implementing a strategy } \\
\text { - Encourage followers to think independently } \\
\text { - Allow followers to make mistakes and learn from them } \\
\text { - Coach or mentor followers } \\
\text { - Strengthen interpersonal trust } \\
\text { - Facilitate problem solving through collaboration }\end{array}$ \\
\hline Team focus & - Create a team-centred environment \\
\hline \multicolumn{2}{|c|}{ Workplace spirituality } \\
\hline $\begin{array}{l}\text { Sense of meaning, } \\
\text { purpose or } \\
\text { transcendence }\end{array}$ & $\begin{array}{l}\text { - Provide feedback to followers on personal strengths and } \\
\text { weaknesses } \\
\text { - Offer fresh perspectives on situations } \\
\text { - Demonstrate respect for leader/followers } \\
\text { - Facilitate followers' professional development } \\
\text { - Indicate how followers make a difference at work }\end{array}$ \\
\hline $\begin{array}{l}\text { Sense of } \\
\text { community or } \\
\text { relatedness }\end{array}$ & $\begin{array}{l}\text { - Value leader-follower relationships beyond their functional } \\
\text { role } \\
\text { - Value all leader/followers as members of the organisational } \\
\text { community }\end{array}$ \\
\hline Work-life balance & $\begin{array}{l}\text { - Enhance followers' work-life balance through shared } \\
\text { organisational values and beliefs } \\
\text { - Actively explore followers' personal values } \\
\text { - Demonstrate concern for followers' work-life balance } \\
\text { - Accommodate emotions and emotional expressions related to } \\
\text { followers' personal lives }\end{array}$ \\
\hline $\begin{array}{l}\text { Supportive } \\
\text { organisational } \\
\text { culture }\end{array}$ & $\begin{array}{l}\text { - Accommodate followers' unique needs and circumstances } \\
\text { - Supply adequate resources } \\
\text { - Affirm followers in their strengths } \\
\text { - Tommunicate openly and transparently } \\
\text { - Tolerate (or even celebrate) mistakes }\end{array}$ \\
\hline $\begin{array}{l}\text { Recognising } \\
\text { followers' holistic } \\
\text { humanity }\end{array}$ & $\begin{array}{l}\text { - Create an environment and opportunities to express various } \\
\text { aspects of followers' being at work } \\
\text { - Treat followers with respect for their knowledge and as human } \\
\text { beings (regardless of the status) } \\
\text { - Express sincere care and concern for leader/followers }\end{array}$ \\
\hline \multicolumn{2}{|c|}{ Cultural inclusivity } \\
\hline $\begin{array}{l}\text { Multicultural } \\
\text { competence }\end{array}$ & $\begin{array}{l}\text { - Be open and sensitive to various cultural interpretations of } \\
\text { meaning }\end{array}$ \\
\hline $\begin{array}{l}\text { Collaborative } \\
\text { leadership }\end{array}$ & $\begin{array}{l}\text { - Creatively motivate young followers (instead of relying on } \\
\text { position) }\end{array}$ \\
\hline \multicolumn{2}{|c|}{ Adapting to advancing communication technology } \\
\hline $\begin{array}{l}\text { Compensating for } \\
\text { lower connection } \\
\text { in virtual } \\
\text { communication }\end{array}$ & $\begin{array}{l}\text { - Proactively invest time and energy in maintaining virtual } \\
\text { leader-follower relationships }\end{array}$ \\
\hline $\begin{array}{l}\text { Participating } \\
\text { professionally in } \\
\text { social media }\end{array}$ & $\begin{array}{l}\text { - Participate actively and professionally on social media } \\
\text { platforms } \\
\text { - Stay abreast of follower communication on social media } \\
\text { forums, and its implications for ILR }\end{array}$ \\
\hline
\end{tabular}

ILR, interpersonal leadership relations.

The findings provided a description of the kind of organisational environment that enhances constructive ILR, a description of constructive ILR and leader/follower attributes that enhance constructive ILR. The findings revealed that an environment that enhances constructive ILR includes a collaborative leadership concept, workplace spirituality, cultural inclusivity and adaptation to advancing communication technology. Within the LFD as a system, it was argued that constructive ILR is marked by the following aspects: active listening, supporting followers as unique individuals, respectful communication, considering followers' perspectives, facilitating a sense of meaning and purpose, role-taking, awareness of attribution, constructive conflict management, fostering constructive relationship properties, and producing constructive system outputs into 
TABLE 4: Constructive interpersonal leadership relations.

\begin{tabular}{|c|c|}
\hline Aspect & Contributing practices or conditions \\
\hline Active listening & $\begin{array}{l}\text { - Listen receptively with concentration } \\
\text { - Demonstrate interest } \\
\text { Reflect literal and emotional understanding of the } \\
\text { message }\end{array}$ \\
\hline $\begin{array}{l}\text { Supporting followers as } \\
\text { unique individuals }\end{array}$ & $\begin{array}{l}\text { - Demonstrate sincere interest in followers' personal } \\
\text { well-being } \\
\text { - Focus on the person behind an issue } \\
\text { - Promote followers' work-life balance } \\
\text { - Listen actively to understand followers' strengths and } \\
\text { needs } \\
\text { - Give feedback to followers on how they contribute } \\
\text { - Make organisational resources available } \\
\text { - Build the follower's credibility with the team } \\
\text { - Mrovide constructive feedback } \\
\text { - Match roles to strengths } \\
\text { Mentor followers }\end{array}$ \\
\hline $\begin{array}{l}\text { Respectful } \\
\text { communication }\end{array}$ & - Treat followers as equal \\
\hline $\begin{array}{l}\text { Considering followers' } \\
\text { perspectives }\end{array}$ & $\begin{array}{l}\text { - Consider all input, regardless of the position } \\
\text { - Practise self-regulation, listening more than talking } \\
\text { - Ask questions to encourage independent thought } \\
\text { - Allow followers to process and contribute information in } \\
\text { their own style } \\
\text { - Facilitate free expression } \\
\text { - Implement valuable follower feedback } \\
\text { - Allow followers to solve problems } \\
\text { - Affirm strengths and contributions verbally }\end{array}$ \\
\hline $\begin{array}{l}\text { Facilitating constructive } \\
\text { redefinition of the } \\
\text { leader/follower's self }\end{array}$ & $\begin{array}{l}\text { - Provide fresh perspectives on situations } \\
\text { - Help followers to gain insights into their strengths and } \\
\text { weaknesses }\end{array}$ \\
\hline $\begin{array}{l}\text { Facilitating a sense of } \\
\text { meaning and purpose in } \\
\text { the leader/follower }\end{array}$ & $\begin{array}{l}\text { - Consider fresh perspectives } \\
\text { - Demonstrate respect } \\
\text { - Facilitate professional growth }\end{array}$ \\
\hline Role taking & $\begin{array}{l}\text { - Perceive the situation from the other's role } \\
\text { - Strive to understand the other's emotions }\end{array}$ \\
\hline $\begin{array}{l}\text { Awareness of } \\
\text { attribution }\end{array}$ & $\begin{array}{l}\text { - Be aware that leader/followers can often attribute each } \\
\text { other's behaviour to certain causes } \\
\text { - Communicate transparently, lessening the need for } \\
\text { attribution }\end{array}$ \\
\hline Conflict management & $\begin{array}{l}\text { - Resolve conflict through respectful, non-threatening and } \\
\text { (if possible) face-to-face communication } \\
\text { - Keep workloads reasonable to allow time for conflict } \\
\text { management }\end{array}$ \\
\hline $\begin{array}{l}\text { Fostering constructive } \\
\text { relationship properties }\end{array}$ & $\begin{array}{l}\text { - Use collaborative and spiritual leadership to build trust } \\
\text { - Accommodate followers as unique individuals } \\
\text { - Resolve conflict through an open, respectful discussion } \\
\text { - Demonstrate personal integrity, credibility and } \\
\text { reliability } \\
\text { - Swop leader/follower roles as required by the situation } \\
\text { - Be receptive and contribute to mutual influence in the } \\
\text { dyad }\end{array}$ \\
\hline $\begin{array}{l}\text { Producing constructive } \\
\text { outputs }\end{array}$ & $\begin{array}{l}\text { - High-quality ILR and Type B leadership may spread to the } \\
\text { organisational climate } \\
\text { - Strong ILR may contribute to employee morale and } \\
\text { engagement } \\
\text { - ILR where followers' performance is supported } \\
\text { contribute to overall job performance } \\
\text { - Constructive ILR may contribute to staff retention }\end{array}$ \\
\hline
\end{tabular}

ILR, interpersonal leadership relations.

the organisation. Finally, leader/follower traits that enhance constructive ILR were discussed in terms of values and competencies.

\section{Contribution and value of the study}

The main contribution of this study is the proposed theoretical framework for ILR. This theoretical framework not only augment the existing knowledge of leadership communication but also substantiate that ILR is an important sub-discipline of communication. Specifically, the centrality of the LFD in a knowledge-based organisation as viewed from a systems perspective and the role of symbolic interaction in and around that dyad were emphasised. Apart from the proposed theoretical framework, the study makes several specific new contributions within each theme and presents an in-depth theoretical understanding of ILR from
TABLE 5: Leader/follower attributes that enhance interpersonal leadership relations.

\begin{tabular}{|c|c|}
\hline \multicolumn{2}{|c|}{ Constructive leader/follower attributes } \\
\hline Value & Behaviour demonstrating the value \\
\hline Honesty & $\begin{array}{l}\text { - Be completely honest } \\
\text { - Fulfil agreements } \\
\text { - Tell the truth about mistakes without excuses }\end{array}$ \\
\hline Love & $\begin{array}{l}\text { - Accommodate followers' personal lives } \\
\text { - Encourage followers in their roles } \\
\text { - Listen to and offer suggestions for followers' professional } \\
\text { challenges } \\
\text { - Credit followers for team successes }\end{array}$ \\
\hline Respect & $\begin{array}{l}\text { - Respect followers for their expertise } \\
\text { - Communicate equally and respectfully with all followers }\end{array}$ \\
\hline Relationships & $\begin{array}{l}\text { - Authentically express the value of relationships } \\
\text { - Communicate directly with followers, instead of delegating } \\
\text { communication }\end{array}$ \\
\hline Trust & $\begin{array}{l}\text { - Believe that others are well-intentioned } \\
\text { - Promote followers' strengths instead of pressurising them } \\
\text { - Demonstrate support }\end{array}$ \\
\hline $\begin{array}{l}\text { Professional } \\
\text { excellence }\end{array}$ & $\begin{array}{l}\text { - Enable leader/followers to achieve mutual goals } \\
\text { - Foster a shared sense of pride in high-quality work } \\
\text { - Demonstrate high-professional standards }\end{array}$ \\
\hline Competency & Behaviour demonstrating the competency \\
\hline Listening skills & $\begin{array}{l}\text { - Be fully present when listening } \\
\text { - Listen calmly with a collegial attitude } \\
\text { - Consider the speaker's context to gain understanding } \\
\text { - Provide feedback on issues raised }\end{array}$ \\
\hline $\begin{array}{l}\text { Emotional } \\
\text { communication } \\
\text { competencies }\end{array}$ & $\begin{array}{l}\text { - Demonstrate self-awareness and self-regulation } \\
\text { - Attend to others' emotions }\end{array}$ \\
\hline Engagement skills & $\begin{array}{l}\text { - Nurture collaboration and flexibility } \\
\text { - Demonstrate care for followers as holistic beings } \\
\text { - Affirm followers in their contributions to the organisation } \\
\text { - Understand that followers need motivation } \\
\text { - Manage conflict and followers' emotions and stress } \\
\text { - Employ collaboraction leadership instead of autocratic } \\
\text { - } \text { leadership } \\
\text { - Adapt to the other leader/follower's communication style }\end{array}$ \\
\hline $\begin{array}{l}\text { Conflict } \\
\text { management skills }\end{array}$ & $\begin{array}{l}\text { - Disagree respectfully } \\
\text { - Discuss conflict transparently } \\
\text { - Brainstorm solutions } \\
\text { - Use humour where suitable }\end{array}$ \\
\hline $\begin{array}{l}\text { Multicultural } \\
\text { competence }\end{array}$ & $\begin{array}{l}\text { - Take others' cultural background into consideration when } \\
\text { communicating with them } \\
\text { - In multinational organisations, be sensitive to the local } \\
\text { culture } \\
\text { - Mentor or coach followers using multicultural skills }\end{array}$ \\
\hline
\end{tabular}

ILR, interpersonal leadership relations.

three different but related perspectives: the organisational environment (Theme 1), the LFD itself (Theme 2) and the individual leader / follower (Theme 3).

\section{Theme 1: The organisational environment}

A collaborative leadership concept was identified as a key construct in enhancing ILR in knowledge-based contexts. The following three shifts in the organisational culture required to enhance ILR were specified: hierarchy to transparency, control to empowerment and an individual focus to a team focus. Two other contributions are the reference made to the term 'relational capacity' of an organisation (referring to the maximum size of an organisation before it becomes too hierarchical to support ILR), and that the physical office environment itself (such as an activitybased office) can flatten the organisational hierarchy and contribute to transparency and engagement.

Although it has been established in communication research that an autocratic leadership concept is limiting or even harmful to knowledge-based contexts and the followers within them, it has also been established that senior leaders 
have a strong influence on the leadership concept in an organisation. However, the research presented a description of how autocratic senior leaders in participants' contexts perpetuate an autocratic leadership concept in the organisation as follows: by enforcing an authoritarian, patriarchal ethnic culture; by modelling to followers that autocratic leadership brings 'ultimate success' in the organisation; by expecting interpersonal leaders to imitate their autocratic leadership style and rewarding them when they do so; by interfering with and counter-influencing the followers of collaborative interpersonal leaders; and by openly ridiculing interpersonal leaders who have a supportive leadership style. Thus, it is argued that interpersonal leaders in autocratic environments exercise collaborative or supportive leadership against great opposition and at great cost.

\section{Theme 2: Symbolic interaction in the leader- follower dyad}

The ILC behaviours that were perceived to be constructive or destructive by participants were identified and described. Four dichotomies emerged that were discussed in conjunction with their typical relational meanings amongst participants, which was emphasised from the relational communication theory view. It was posited that participants who received aggressive communication experienced a wide range of negative emotions, together with a loss of confidence and the sense that their opinion was not valued. By contrast, those who received respectful communication felt confident, respected and motivated, and believed that their opinion was valued. Furthermore, being blocked from communicating made participants feel silenced and even 'useless', whilst verbal affirmation of their strengths and contributions made them feel motivated and valued. Thirdly, inattentiveness by their leader/followers led them to feel disrespected, unimportant or even angry. By contrast, when their leader/ followers listened actively to them, they felt valued, empowered, and - interestingly - both trusted and trusting. Fourthly, indirect communication from their leader/ followers frustrated them, whilst supportive communication gave them a sense of confidence and worth and motivated them to do their work well and even pursue more responsibility.

This study also identified the types of attributions to destructive ILC by leader/followers to indicate whether leader/ followers view these attributions as acceptable reasons for the destructive behaviour. Work pressures (concern with the quality or prompt completion of the task) and low EQ (low emotional intelligence, or personal insecurity) were the attributions most often cited. Notably, participants tended to view work pressures as an acceptable reason for negatively perceived behaviour, whilst low EQ was generally not tolerated as an explanation for such behaviour. A pattern was also detected where participants who believed the reasons they attributed to their leader/followers' destructive behaviour were acceptable explanations for such behaviour, also had positive attitudes towards their LFDs. In terms of role taking (empathy), it was found that participants were generally very understanding of their leader/followers (given the latter's circumstances) and tolerant of even destructive behaviour. In addition, participants emphasised the importance of understanding the other leader/follower's emotions as an important aspect of role taking.

Typical approaches to conflict management in LFDs included how participants perceived the approach in their dyad. The most prevalent and by far the most preferred approach was non-threatening, respectful face-to-face discussion, which was considered as the approach most likely to increase the quality of interaction and collaboration in the dyad. Two other common approaches were being submissive (perceived extremely negatively) and avoiding or withdrawing from the conflict (perceived mostly negatively). It is also noteworthy that some participants reported that heavy workloads interfered with their ability to invest time and energy to fully resolve interpersonal conflict. Leader/ followers experienced a greater sense of meaning or purpose by experiencing the following because of symbolic interaction in the dyad: a sense of making a difference or contributing to a larger goal; experiencing professional growth; experiencing personal growth; and feeling respected, appreciated or useful. Notably, the degree to which leader/ followers experience a sense of meaning or purpose at work may also influence their decisions to remain in or leave the organisation.

\section{Theme 3: Leader/follower attributes that enhance interpersonal leadership relations}

The leader/follower values that contributed to constructive ILR were found to be honesty (also integrity, transparency, trustworthiness, ethical conduct or credibility), love (also care or supportiveness), respect, relationships (also communication and engagement), trust and professional excellence (described by several participants as good 'work ethic'). It was found that trust requires personal beliefs in contrast with those typically held by autocratic leaders. An example of a constructive belief is the belief that people are basically good, well-intentioned and trustworthy. The leader/follower competencies that enhanced ILR were the following: listening skills (viewed as central by most participants), emotional communication competencies (particularly self-awareness, self-reflection and attending to others emotions), engagement skills, conflict management skills and multicultural competence (including generational skills).

\section{Contributions and limitations of the study}

The main contribution of this study is the new proposed theoretical framework that confirmed the usefulness of the systems theory and SI as valuable metatheories to explore ILR. From a managerial perspective, the theoretical framework can be used for interpersonal leadership training interventions, and as a valuable guide for appointing new leader/followers in the organisation. 
The main limitation is that it is a qualitative study based on two relatively small convenience samples, and therefore, the findings of this study cannot be generalised to a wider population. Yet, according to Ethiraj, Gambardella and Helfat (2016, p. 2191), 'exact replication is not likely to be the most interesting form of replication in strategic management research ... it is mostly interested in "quasi-replications", which address the "robustness of prior studies to different empirical approaches or the generalisability of prior study's findings to new contexts".' Using the social constructionist perspective in this study, in which it is asserted that knowledge and theory cannot be generalised and universally applied, allows for quasi-replications through a combination of conceptual (same population and different procedures which can be generalised) and/or empirical (same procedures and a different population) replications. Any theory can thus be only a partial reflection of a social reality that is too complex to be represented in a single theory (Svensson, 2009, p. 192). It is also acknowledged that ILR in knowledge-based organisational contexts is too complex a phenomenon to definitively represent in a single theory. However, it is posited that the theoretical framework presented in this study provides useful guidelines for its practice.

This was a cross-sectional study in that the data were collected at a specific point in time and not over a prolonged period. Hence, the proposed theoretical framework was divided into a general model and a more detailed and specific framework for constructive ILR. The general model presents a generic overview based on a sound theoretical underpinning that already possess longevity that strengthens the feasibility thereof but will need to be reviewed in future.

As self-reported viewpoints were used (information on ILR was not collected directly), the findings only reflected participants' perceptions of ILR in their experience. However, objectivity was not the aim of this study, which instead had a phenomenological focus. It is argued that the representation of participants' lived experiences makes a significant contribution to the discipline of communication.

\section{Recommendations for further research}

It is recommended that this study be repeated over time with diverse samples to test and modify the theoretical framework, especially from international and multicultural perspectives. In addition, specific aspects of the framework may be tested through quantitative research employing larger samples. As the focus of this study was dyadic, the research exploring team dynamics related to ILR in small teams will make a valuable contribution.

\section{Conclusion}

Given the apparent complexities of ILR in knowledge-based organisations, it seems important to acknowledge the intrinsic heterogeneity and multiplicity of the concept, as well as the implications thereof. Whilst some organisations may lend themselves naturally to the implementation of the constructs highlighted in the theoretical framework, in other contexts the complexity of fostering constructive ILR may present a greater challenge.

To conclude, given the scarcity of research studies on this topic, this article is an important starting point for future research to clarify and consider the wider implications of ILR in theory and in practice, where the former may evoke enhancements in research, in general, and the latter may be across different areas and sectors. In this way, the different approaches can be investigated in different contexts and allow researchers to present complementary frameworks (or even measuring instruments) for the systematic analysis thereof. Whilst this article outlined some of the basic concepts and approaches, much remains to be carried out and several options exist to extend this research. This is reflected in the following words of one of the participants in the study:

'Good IRL as defined by the [study], is a constructive force in the workplace not only in terms of human relations, but also in terms of the work environment functioning more efficiently ... if people believe in the meaning of what they do, and in the value of the people they work with and work for, it will deliver greater synergy and energy to the work quality and environment.' (Female participant, Questionnaire 29)

\section{Acknowledgements Competing interests}

The authors declare that they have no financial or personal relationships that may have inappropriately influenced them in writing this article.

\section{Authors' contributions}

The article is based on a completed PhD of Dr M.L. under supervision of R.B. The draft article was compiled and written by M.L. R.B. updated the draft article, added relevant information, finalised or edited the article, formatted it in the required format and submitted it.

\section{Ethical considerations}

This article followed all ethical standards for a research without any direct contact with human or animal subjects.

\section{Funding information}

This research work received no specific grant from any funding agency in the public, commercial or not-for-profit sectors.

\section{Data availability}

The data that support the findings of this study are available from the corresponding author, Rachel Barker, upon reasonable request. 


\section{Disclaimer}

The views expressed in the submitted article are those of the author and not an official position of the institution or funder.

\section{References}

Alban-Metcalfe, J., \& Alimo-Metcalfe, B. (2013). Reliability and validity of the leadership competencies and engaging leadership scale. International Journal of Public Sector Management, 26(1), 56-73. https://doi. org/10.1108/09513551311294281

Anguinis, H., \& Solariono, A.M. (2019). Transparency and replicability in qualitative research: The case of interviews with elite informants. Strategic Management Journal, 4O(8), 1291-1315. https://doi.org/10.1002/smj.3015

Ary, D., Jacobs, L.C., Irvine, C.K.S., \& Walker, D.A. (2018). Introduction to research in education (10th ed.). Boston, MA: Cengage.

Barrett, D.J. (2006). Strong communication skills a must for today's leaders. Handbook of Business Strategy, 7(1), 385-390. https://doi.org/10.1108/10775730610619124

Bazeley, P. (2013). Qualitative data analysis: Practical strategies. London: Sage.

Blake, N., Leach, L.S., Robbins, W., Pike, N., \& Needleman, J. (2013). Healthy work environments and staff nurse retention: The relationship between communication, collaboration, and leadership in the pediatric intensive care unit Nursing Administration Quarterly, 37(4), 356-370. https://doi.org/10.1097/ NAQ.0b013e3182a2fa47

Bryman, A., \& Bell, E. (2015). Business research methods (4th ed.). Oxford: Oxford University Press.

Burns, T.R., \& DeVillé, P. (2017). Socio-economics: The approach of social systems theory in a forty-year perspective. Economics and Sociology, 10(2), 11-20. https:// doi.org/10.14254/2071-789X.2017/10-2/1

Cassell, C. (2015). Conducting research interviews for business and management students. London: Sage.

Collis, J., \& Hussey, R. (2017). Cost and management accounting. London: MacMillan Press Ltd.

Ethiraj, S.K., Gambardella, A., \& Helfat, C.E. (2016). Replication in strategic management. Journal of Strategic Management, 37(11), 2191-2192. https://doi. org/10.1002/smj.2581

Gentry, W., \& Sparks, T. (2012). A convergence/divergence perspective of leadership competencies managers believe are most important for success in organizations: A cross-cultural multilevel analysis of 40 countries. Journal of Business and Psychology, 27(1), 15-30. https://doi.org/10.1007/s10869-011-9212-y

Gill, R. (2011). Theory and practice of leadership. London: Sage.

Glynn, M.A., \& DeJordy, R. (2010). Leadership through an organization behavior lens. In N. Nohria \& R. Khurana (Eds.), Handbook of leadership theory and practice: A
Harvard Business School centennial colloquium (pp. 119-160). Boston, MA: Harvard Business School
Harvard Business Press.

Goffee, R., \& Jones, G. (2013). Cameo: Authentic followership in the knowledge economy. In D. Ladkin \& C. Spiller (Eds.), Authenticleadership: Clashes, convergences and coalescences (pp. 208-219). Cheltenham: Edward Elgar Publishing.

Hackman, M.Z., \& Johnson, C.E. (2013). Leadership: A communication perspective (6th ed.). Long Grove, IL: Waveland Press.

Hoption, C. (2014). Learning and developing followership. Journal of Leadership Education, 13(3), 129-137.

Howell, J., \& Shamir, B. (2005). The role of followers in the charismatic leadership process: Relationships and their consequences. Academy of Management Review, 30(1), 96-112.

Indriati, F., Tjakraatmadja, J.H., Rudito, B., \& Thoha, N. (2016). An integrated framework of the antecedents of knowledge-sharing behavior among lecturers. Sains Humanika, 8(1-2), 25-31. https://doi.org/10.11113/sh.v8n1-2.828
Jarrahi, M.H., \& Thomson, L. (2017). The interplay between information practices and information context: The case of mobile knowledge workers. Journal of the Association for Information Science and Technology, 68(5), 1073-1089. https:// Association for Information
doi.org/10.1002/asi.23773

Johansson, C., Miller, V., \& Hamrin, S. (2014). Conceptualizing communicative leadership. Corporate Communications: An International Journal, 19(2), 147-165. https://doi.org/10.1108/CCIJ-02-2013-0007

Littlejohn, S.W., \& Foss, K.A. (2008). Theories of human communication (9th ed.). Belmont, CA: Wadsworth.

Locke, F., Silverman, J., \& Spirduso, W. (2010). Reading and understanding research. Newberry Park, CA: Sage.

Maree, J. (2012). The ultimate aim of your studies: Getting a manuscript published. In J. Maree (Eds.), Complete your thesis or dissertation successfully: Practical guidelines (pp. 210-243). Cape Town: Juta.

McDermott, V. (2009). Interpersonal communication theories. In S. Littlejohn \& K. Foss (eds.), Encyclopedia of communication theory (pp. 546-551). Thousand Oaks, CA: Sage.

Miller, K. (2002). Communication theories: Perspectives, processes, and contexts. New York, NY: McGraw-Hill.

Mitchell, C. (2014). Leadership communication skills in a contemporary organisation: Towards a conceptual framework. Unpublished doctorate. Bloemfontein: University of the Free State.

Piccolo, R., Greenbaum, R., Den Hartog, D., \& Folger, R. (2010). The relationship between ethical leadership and core job characteristics. Journal of Organizational Behavior, 31(2-3), 259-278. https://doi.org/10.1002/job.627

Riggio, R., \& Lee, J. (2007). Emotional and interpersonal competencies and leader development. Human Resource Management Review, 17(4), 418-426. https:// doi.org/10.1016/j.hrmr.2007.08.008

Rokeach, M. (1973). The nature of human values. New York, NY: Free Press.

Ritchie, J., Lewis, J., Elam, G., Tennant, R., \& Rahim, N. (2014). Designing and selecting samples. In J. Ritchie, J. Lewis, C. McNaughton Nicholls \& R. Ormston (Eds.), Qualitative research practice: A guide for social science students and researchers Qualitative research practice: A guide for
(pp. 111-145). Thousand Oaks, CA: Sage.

Ryan, G., \& Bernard, H. (2003). Techniques to identify themes. Field Methods, 15, 85-109. https://doi.org/10.1177/1525822X02239569

Saldaña, J. (2016). The coding manual for qualitative researchers (3rd ed.). London: Sage.

Schutz, A. (1967). The phenomenology of the social world. Evanston, IL: Northwestern University Press.

Seidman, I. (2013). Interviewing as qualitative research: A guide for researchers in education \& the social sciences (4th ed.). New York: Teachers College Press.

Serrat, O. (2017). Knowledge solutions. Singapore: Springer.

Shenton, A.K. (2004). Strategies for ensuring trustworthiness in qualitative research projects. Education for Information, 22(2), 63-75. https://doi.org/10.3233/EFI2004-22201

Svensson, G. (2009). A counter intuitive view of the deductive research process: Clockwise versus anti-clockwise approaches. European Business Review, 21(2), 191-196. https://doi.org/10.1108/09555340910940178

Tannenbaum, R., Weschler, I.R., \& Massarik, F. (2013). Leadership and organization: A behavioural science approach. Abingdon: Routledge.

Testa, M., \& Sipe, L. (2012). Service-leadership competencies for hospitality and tourism management. International Journal of Hospitality Management, 31(3) 648-658. https://doi.org/10.1016/j.ijhm.2011.08.009

Watzlawick, P., Beavin Bavelas, J., \& Jackson, D. (2011). Pragmatics of human communication: A study of interactional patterns, pathologies, and paradoxes. New York: WW Norton \& Company.

Winkler, I. (2010). Contemporary leadership theories: Enhancing the understanding of the complexity, subjectivity and dynamic of leadership. Heidelberg: SpringerVerlag Berlin Heidelberg. 